\title{
Pre-Hospital Delay in Patients With Acute Chest Pain
}

\author{
Lidija D Milovanović, ${ }^{1}$ Slavoljub R Živanović²
}

\begin{abstract}
Introduction: Incidence of chest pain and discomfort varies in general population between $2 \%$ and $5 \%$. Total prehospital delay involves two components: the time it takes for patients to recognise their symptoms as severe and seek medical attention, ie the decision-making time, and the time from seeking help to hospital admission, ie the transport time. Scope of the study was to analyse time loss in patients with chest pain hesitating to contact healthcare services, as well as distribution of acute myocardial infarction (AMI) and angina pectoris (AP) among them.

Methods: Retrospective analysis of medical records of physicians working at the emergency medical services (EMS) Department of the City of Belgrade, Serbia, from 20 April 2006 to 22 July 2013 on a total of 5,310 completed field interventions. When placing a call to the EMS, $10.43 \%$ of patients cited chest pain as a major symptom. After deducting all those ones who denied having the symptom on examination thereafter and those for whom there were no data, 349 patients remained, ie $6.57 \%$ of the total number of calls available for analysis.

Results: The average time between the onset of chest pain and the decision to call the EMS was $11.97 \mathrm{~h}$, median $2 \mathrm{~h}$ and mode $1 \mathrm{~h}$. Patient's minimum prehospital delay was $2 \mathrm{~min}$ and the maximum was 20 days. Most patients who experienced chest pain or discomfort waited less than an hour before calling the EMS. Most commonly diagnoses made for a symptom of chest pain were AMI and AP, ie AMI with $12.32 \%$ of the total diagnoses, as well as the elevated arterial pressure. There were more female patients, with no difference found among the age groups.

Conclusion: For the majority of patients with chest pain and discomfort presented in this paper the decision-making time was up to one hour, with cardiovascular causes being the at the top of the list.
\end{abstract}

Key words: Chest pain; Primary health care; Pre-hospital delay; Time, Emergency medical services; Pre-hospital.

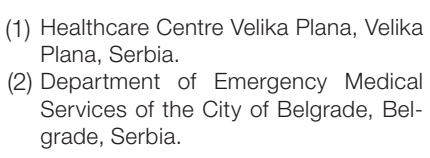

1) Healthcare Centre Velika Plana, Velika Plana, Serbia.

(2) Department of Emergency Medical Services of the City of Belgrade, Belgrade, Serbia.

\section{Correspondence:}

SLAVOLJUB ŽIVANOVIĆ

E: slavoljubz3@mts.rs

M: +381642939324

\section{ARTICLE INFO}

Received: 10 January 2020

Revision received: 23 May 2020 Accepted: 27 May 2020

\section{Introduction}

Chest pain is a common problem and up to $25 \%$ of the general population experience it during their lifetime. ${ }^{1}$ Non-traumatic chest pain is a common symptom in clinical practice and is one of the most commonly reported complaints of patients in emergency medical services with a prevalence of 2-6\%.-4 Numerous aetiological factors can cause chest pain, from life-threatening conditions to others that do not represent an immediate threat to patients' lives. Causes of chest pain may be of cardiovascular, pulmonary, neurological, gastrointestinal, musculoskeletal or psychiatric origin. ${ }^{2,5}$

Although most patients with chest pain have other non-life-threatening conditions, in approximately $10-20 \%$ of cases, patients suffer from the acute coronary syndrome (ACS) requiring early intervention and treatment. ${ }^{3,6}$ The most serious and common causes of chest pain are ACS, aor- 
tic dissection, pulmonary embolism, rupture of an aortic aneurysm and tension pneumothorax. ${ }^{2}$ Many factors, including demographics, as well as clinical and social components, are responsible for the delay in patient's decision making process to seek immediate medical attention. ${ }^{7,8} \mathrm{Nu}-$ merous studies indicate that it is very difficult for patients to recognise whether chest pain is of cardiac or non-cardiac origin. ${ }^{9}$ Early referral of possible acute myocardial infarction (AMI) to hospitals is crucial for survival and subsequent quality of life..$^{10}$ Various studies have been conducted on prehospital delay in patients with chest pain.9, 11 Observational studies indicate that a number of factors may be associated with patients' delay in seeking medical attention for non-traumatic chest pain. These factors include: demographics (gender, age, race), clinical (history of chronic illnesses and previous myocardial infarction) and social factors (neighbour/layman advice, occurrence outside of home, living alone, resting or sleeping during a cardiac event, feeling embarrassed). ${ }^{8,12}$ Pain intensity may not be a significant factor in the diagnosis of AMI. ${ }^{13}$

Total prehospital delay involves two components: the time it takes for patients to recognise their symptoms as severe and seek medical attention, ie the decision-making time, and the time from seeking help to hospital admission, ie the transport time. ${ }^{14}$ Research indicates that the time elapsed while patients are making a decision whether to seek medical attention is a larger component and strategies for reducing the patient delays must target exactly this component. ${ }^{15-18}$ The recommendations of the American Heart Association are that "patients who have been experiencing symptoms of myocardial infarction for 5-10 minutes should seek immediate medical attention".11 "Early administration of thrombolytic therapy reduces infarct size and improves survival. Its administration within one hour of symptom onset reduces mortality by 45 $\%$ and by $23 \%$ if administered within $3 \mathrm{~h}$. ${ }^{9}$

In the EMS Department of the City of Belgrade a medical doctor is a compulsory member of each EMS team and each ambulance is equipped with an electrocardiograph machine (ECG) and the equipment for cardiopulmonary resuscitation.

Scope of the study was analysis of patients' decision-making time since the onset of chest pain until they make a call to the EMS, evaluation of diagnoses made by the ambulance team and analysis of patients diagnosed with acute coronary syndrome (ACS).

\section{Methods}

The study is a retrospective analysis of medical records of physicians working at the EMS Department, Belgrade, Serbia on completed field interventions, from 20 April 2006 to 22 July 2013. Data were taken from the physician's call form completed for each attended patient and was then entered into an Excel database, which was then searched and sorted. Patient's age, gender, duration of symptoms, previous medical history, as well as prescribed therapy were recorded, without the identification data such as patient's name and address. Included in the study were those patients whose main complaint was pain or other discomfort suspective of chest pain at the moment when their call was taken by the EMS call centre. Out of the total number, patients that denied on examination they were experiencing any chest pain were excluded. There were some patients for whom this information was not entered and therefore they were excluded from the study as well. There were 349 patients with complaint of chest pain as their main symptom, for which they were able to provide accurate information about when the problems had started.

In the study group the time elapsed from the onset of chest pain to the time they made a call to the EMS Department, Belgrade was analysed. Times were calculated based on patients' explanations about when exactly the chest pain had started. For ease of interpretation, depending on the duration of the complaint until they made a call to EMS, patients were divided into groups: $\leq$ $1 \mathrm{~h}, 1-2 \mathrm{~h}, 2-24 \mathrm{~h},>24 \mathrm{~h}$.

The diagnosis of AMI was made based on medical history taken during examination, ECG records and other medical records available from patients. Diagnosis of newly present angina pectoris (AP) was made in patients, as well as prolonged AP and angina with altered character of complaints. In patients with AMI and AP, the gender difference in calling EMS was analysed. Those patients were divided into groups based on the time elapsed from the onset of pain until calling for an ambulance: $\leq 1 \mathrm{~h}, 1-2 \mathrm{~h}, 2-24 \mathrm{~h}$ and 
$>24$ h. All patients underwent a medical examination and ECG testing.

The data were processed using IBM SPSS 21.0 software. Results are presented as mean \pm standard deviation (SD) and median or mode. Statistical testing was done with the Chi-square test and descriptive statistics. The diagnoses in this study represent working, not definitive diagnoses.

\section{Results}

Of the 5,310 interventions, a total of 554 calls received by the call centre were with major complaint of chest pain, which accounted for $10.43 \%$ of all interventions. There were 349 patients with complaint of chest pain as their main problem, for which they were able to provide accurate information about when the problems had started, which makes $6.57 \%$ of the total number of calls that were included in the analysis.

Gender and age structure are presented in Table 1 . When comparing younger and older patients (up to 65 years and $\geq 65$ ), there were no statistical significance $\left(\chi^{2}=0.84, p>0.05\right)$, as well as by gender $\left(\chi^{2}=0.84, p>0.05\right)$. When comparing older and younger age representation in the female patient group, there were statistically significantly more elderly patients $\left(\chi^{2}=9.97, \mathrm{p}<\right.$ 0.01). When comparing younger and older male patients, there was no statistically significant difference $\left(\chi^{2}=0.44, p>0.05\right)$.

Table 1: Gender and age distribution of patients with chest pain

\begin{tabular}{|c|c|c|c|c|c|c|c|}
\hline \multirow[t]{2}{*}{ Gender } & \multirow[t]{2}{*}{$\mathbf{N}$} & \multirow[t]{2}{*}{$\%$} & \multicolumn{5}{|c|}{ Age } \\
\hline & & & $\geq 65$ & $>65$ & Total & Range & Mean \pm SD \\
\hline Male & 147 & 42.12 & 77 & 69 & 146 & $25-95$ & $62 \pm 14$ \\
\hline Female & 196 & 56.16 & 76 & 119 & 195 & $32-88$ & $67 \pm 12$ \\
\hline Unknown* & $3+3$ & 1.72 & $6+2$ & & 8 & & \\
\hline Total & 349 & 100 & 153 & 188 & 349 & $25-95$ & $64.53 \pm 13.19$ \\
\hline
\end{tabular}

The average time between the onset of chest pain and the decision to call an ambulance was 11.97 $\mathrm{h}$ (range $2 \mathrm{~min}-20$ days), median $2 \mathrm{~h}$ and mode 1 h. Older patients waited longer to make the call to EMS. There was no statistically significant gender difference in all the groups based on duration of chest pain before calling the EMS ( $p>0.05$ ) (Table 2).
Table 2: Duration of chest pain before calling Emergency Medical Service Belgrade with gender and age distribution

\begin{tabular}{|c|c|c|c|c|c|c|c|}
\hline \multirow[t]{2}{*}{ Time } & \multirow[t]{2}{*}{$\mathbf{N}$} & \multirow[t]{2}{*}{$\%$} & \multicolumn{3}{|c|}{ Gender } & \multirow[b]{2}{*}{$\%$} & Age \\
\hline & & & Female (N) & $\%$ & Male (N) & & Mean \pm SD \\
\hline Up to $1 \mathrm{~h}$ & 152 & 43.55 & 74 & 37.76 & 74 & 50.34 & $61.89 \pm 13.09$ \\
\hline $1-2 \mathrm{~h}$ & 47 & 13.47 & 29 & 14.8 & 17 & 11.56 & $64.50 \pm 10.30$ \\
\hline $2-24 h$ & 117 & 33.52 & 72 & 36.73 & 45 & 30.61 & $67.25 \pm 13.21$ \\
\hline Over $24 \mathrm{~h}$ & 33 & 9.46 & 21 & 10.71 & 11 & 7.49 & $67.45 \pm 15.16$ \\
\hline Total & 349 & 100 & 196 & 100 & 147 & 100 & $64.53 \pm 13.19$ \\
\hline
\end{tabular}

For 3 patients there were no gender data, for 2 patients there is no age data and for 3 patients there were neither age nor gender data.

ACS, ie AMI and AP, accounted for $45 \%(n=157)$ of all diagnoses (Table 3). Non-cardiovascular diseases accounted for $31.5 \%$, with severe pain and muscle cramps. Other cardiovascular diseases that were the cause of or were interpreted by patients as chest pain accounted for $23.52 \%(n=82)$ of cases. In this category increased blood pressure was most common with $10.89 \%$ of cases. Duration of chest pain before calling EMS based on diagnosis is shown in Table 4.

The average time from the onset of chest pain to making a call to the EMS for patients with ACS, was $7.6 \mathrm{~h}$, median $0.5 \mathrm{~h}$. The average time for AMI, was $6.3 \mathrm{~h}$ (median $0.5 \mathrm{~h}$ ) and for AP $7.6 \mathrm{~h}$ (median $0.5 \mathrm{~h})$. The majority of these patients $(43.55 \%, \mathrm{n}=$ 152) were in the group who had waited up to one

Table 3: Causes of chest pain based on diagnoses made by the emergency medicine service team in the field

\begin{tabular}{|c|c|c|}
\hline Diagnosis & $\mathbf{N}$ & $\%$ \\
\hline Acute coronary syndrome & 157 & 45 \\
\hline Acute myocardial infarction & 43 & 12.32 \\
\hline Angina pectoris & 114 & 32.66 \\
\hline Other Cardiovascular Diseases & 82 & 23.5 \\
\hline Hypertension & 38 & 10.89 \\
\hline Rhythm disorders & 30 & 8.6 \\
\hline Heart failure & 12 & 3.44 \\
\hline Cardiac arrest with successful resuscitation & 1 & 0.29 \\
\hline Sudden death due to cardiac arrest & 1 & 0.29 \\
\hline Non-Cardiovascular Causes & 110 & 31.52 \\
\hline Severe pain and spasm & 45 & 12.89 \\
\hline Abdominal and pelvic pain & 10 & 2.87 \\
\hline Throat and chest pain & 12 & 3.44 \\
\hline Instability and dizziness & 2 & 0.57 \\
\hline Syncope and collapse & 9 & 2.58 \\
\hline Nausea and vomiting & 2 & 0.57 \\
\hline Respiratory system* & 12 & 3.44 \\
\hline Other** & 18 & 5.16 \\
\hline Total & 349 & 100 \\
\hline \multicolumn{3}{|c|}{$\begin{array}{l}N=\text { number of patients; } \%=\text { percentage of patients } \\
\text { * Respiratory system (cold, respiratory failure, chronic obstructive pulmonary disease, chronic } \\
\text { bronchitis, pneumonia, shortness of breath) } \\
\text { *^ Other: Z03, unstable joint, cystic watery hernia, mental or behavioural disorders caused } \\
\text { by alcohol use, gallbladder stone without gallbladder inflammation, fever of unknown origin, } \\
\text { apoplexy, severe stress reaction, joint inflammation. }\end{array}$} \\
\hline
\end{tabular}


Table 4: Distribution of pre-hospital delays in patients with chest pain based on the diagnosis

\begin{tabular}{|c|c|c|c|c|c|c|}
\hline \multirow[t]{2}{*}{ Time } & \multicolumn{6}{|c|}{ Diagnosis: N (\%) } \\
\hline & AMI & AP & \multicolumn{2}{|c|}{ Other CVD } & Non-CVD & Total (N) \\
\hline Up to $1 \mathrm{~h}$ & 27 (17.76) & 57 (37.50) & $24(15$ & 5.79) & 44 (28.95) & 152 \\
\hline $1-2 \mathrm{~h}$ & $3(6.38)$ & $16(34.04)$ & $13(27$ & 7.66) & $15(31.91)$ & 47 \\
\hline $2 \mathrm{~h}$ to $24 \mathrm{~h}$ & $12(10.26)$ & 34 (29.06) & $32(27$ & 7.66) & 39 (33.33) & 117 \\
\hline Over $24 \mathrm{~h}$ & 1 (3.03) & $7(21.21)$ & $13(39$ & 9.39) & $12(36.36)$ & 33 \\
\hline Total & 43 (12.32) & $114(32.49)$ & $82(23$ & 3.49) & $110(31.52)$ & 349 \\
\hline \multicolumn{7}{|c|}{$\begin{array}{l}N=\text { number of patients, } \%=\text { percentage of patients } \\
A M I=\text { acute myocardial infarction, } A P=\text { angina pectoris } \\
\text { Other } C V D=\text { cardiovascular diseases with the exception of } A M I \text { and } A P, \text { Non- } C V= \\
\text { non-cardiovascular causes of chest pain }\end{array}$} \\
\hline \multicolumn{7}{|c|}{$\begin{array}{l}\text { hour from the onset of chest pain before calling for } \\
\text { an ambulance. The average decision time was sig- } \\
\text { nificantly shorter when a patient with AMI who } \\
\text { sought help after } 24 \mathrm{~h} \text { from the onset of chest } \\
\text { pain was excluded and the average time was then } \\
2.02 \mathrm{~h} \text {. }\end{array}$} \\
\hline \multicolumn{7}{|c|}{$\begin{array}{l}\text { Table 5: Gender and age distribution in patients with acute myo- } \\
\text { cardial infarction and angina pectoris }\end{array}$} \\
\hline \multirow[t]{2}{*}{ Gender } & & ACS & \multicolumn{2}{|c|}{ AMI } & \multicolumn{2}{|c|}{ AP } \\
\hline & $\mathrm{N}$ & $\%$ & $\mathrm{~N}$ & $\%$ & $\mathrm{~N}$ & $\%$ \\
\hline Male & 79 & 50.31 & 27 & 62.8 & 52 & 45.61 \\
\hline$<65$ years & 41 & 26.11 & 14 & 32.56 & 27 & 23.68 \\
\hline$\geq 65$ years & 37 & 23.57 & 12 & 27.91 & 25 & 21.93 \\
\hline Female & 74 & 47.13 & 16 & 37.21 & 58 & 50.88 \\
\hline$<65$ years & 27 & 17.18 & 5 & 11.63 & 22 & 19.30 \\
\hline$\geq 65$ years & 47 & 29.94 & 11 & 25.58 & 36 & 31.58 \\
\hline Unknown & 5 & 3.18 & 1 & 2.33 & 4 & 3.51 \\
\hline Total & 157 & 100 & 43 & 100 & 114 & 100 \\
\hline
\end{tabular}

$N=$ number of patients; $\%=$ percentage of patients

$A C S=$ acute coronary syndrome, $A M I=$ acute myocardial infarction, $A P=$ angina pectoris For three patients there were no data on their gender, for two patients there were no data on their age and for three patients there were no data on either gender or age

Considering ACS, there was no statistical difference between genders and age $(p>0.05)$, except for AMI where there was greater number of females over 65 years of age compared to those un$\operatorname{der} 65\left(\chi^{2}=5.83, \mathrm{p}<0.05\right)$ (Table 5). Male patients with AMI were younger, but the difference was not statistically significant. A higher percentage of men who complained of chest pain had AMI in comparison to females (62.8 \% vs $37.2 \%$ ), however no statistical significance was found.

\section{Discussion}

In this study, every tenth patient who called an EMS complained of chest pain. However, when those interventions in which chest pain was quoted as reason for calling the EMS were excluded from this study and patients denying such a complaint later on the scene, then the remaining re- sult was $8.44 \%$, which is still higher than in the prevalence of chest pain in the emergency services of Pretoria, South Africa. ${ }^{1}$

"Recent studies examining the differences in the proportion of males and females with AMI who call for an ambulance have found inconsistent results. While some studies have found that there is no difference between males and females with AMI when calling for EMS, other studies targeting patients with AMI have found that women are more likely to call for emergency medical services than men". ${ }^{19}$ In this study, almost equal percentages of males and females called the EMS and when it comes to aggregate AMI and AP diagnoses, with no statistical significance. When comparing females older and younger than 65 years of age, the incidence of females over 65 was higher, although the comparison number was relatively small.

The average time between the onset of chest pain and the decision to call for an ambulance in this study was $11.97 \mathrm{~h}$, with a median of two hours, which is longer than the study by Kathleen et $\mathrm{al}^{16}$ where this time was $9.14 \mathrm{~h}$, median $1.90 \mathrm{~h}$. The largest number of patients with chest pain in this study ( $\mathrm{n}=152$ or $43.55 \%$ ) were in the group in which the time interval between the onset of chest pain and placing a call to the EMS was $\leq 1$ $h$. These data differ significantly from the study conducted in Belgium by Van Severen et al, ${ }^{10}$ where only $9 \%$ of patients were in the group where the time between the onset of chest pain and hospitalisation was $<1 \mathrm{~h}$. According to their results, the largest number of patients, ie $32 \%$, arrived at the hospital after 3-12 h since the onset of the complaint, whereas in this study, 33.5 $\%$ or 117 patients, decided in the time interval of 2-24 $\mathrm{h}$ from the onset of pain to call the EMS. ${ }^{10}$ The largest number of patients with chest pain in the present study was in the group who waited up to one hour to make a call the EMS and the lowest percentage of patients $(9.45 \%)$ decided to call the EMS in the time interval of $24-48 \mathrm{~h}$ after the onset of symptoms. There were $9.45 \%$ of patients in the group that waited $\geq 24 \mathrm{~h}$. In this group, there was also one patient who stated that his pain had been lasting all the time.

Numerous observational studies indicate a significant time delay in deciding to call for an ambulance from the onset of chest pain. Mumford et $\mathrm{al}^{18}$ received an average waiting time of 172 minutes for their patients with AMI, and $25 \%$ of 
them called for medical help within one hour of symptom onset, which is significantly lower than in this study where this percentage was $62.8 \%$. Coventry et $\mathrm{al}^{11}$ found that the median prehospital delay time had been $3.9 \mathrm{~h}$, with only $3.9 \%$ of patients contacting the EMS within one hour. A significant percentage of their patients $(12.2$ $\%$ ) waited longer than $24 \mathrm{~h}$ to seek medical help, while in the study presented here only one patient or $2.3 \%$ was registered in this time period.

In the present study, almost half of the patients ( $45 \%$ or 157) were diagnosed with AMI or AP, while in Van Severe et al study, the percentage of patients with AMI was $35 \%{ }^{10}$ The percentage of cardiovascular events as cause of chest pain is approximately the same in both studies, while the percentage of non-cardiovascular events was lower in Van Severe et al study than in this study (31.52\% vs $45 \%) .{ }^{10}$ In patients with AMI, the average waiting time from the onset of chest pain to making a call to the EMS in this study in this paper was $7.6 \mathrm{~h}$, median $0.5 \mathrm{~h}$, while in the study by Porras et $\mathrm{al}^{14}$ this time was $3.6 \mathrm{~h}$, median $50 \mathrm{~min}$. In a study by Coventry et $\mathrm{al}^{11}$ the median prehospital time delay in patients with AMI varied from $1.2 \mathrm{~h}$ to $7.2 \mathrm{~h}$.

There was no statistically significant difference in calling for ambulance between males and females with ACS, ie AMI and AP together, which is not in line with the study conducted by Newman et al. ${ }^{19}$ In their study, in patients with AMI, females were significantly more likely to call for an ambulance (females $57 \%$ vs males $28.2 \%$ ), while in the group of patients with AMI presented in this paper there were more males - males $62.8 \%$ vs $37.2 \%$ of females, but with no statistical significance (small number of patients), although there was also a difference in methodology.

\section{Conclusion}

Most delays in seeking appropriate treatment occur prior to patients' contact with medical services. Although the majority of patients in this study were in the group who had waited up to one hour from the onset of chest pain before calling for an ambulance, the average time was still unsatisfactory. Strategies for reducing the patient delays must target exactly this component, ie reducing the time in which patients decide to seek medical attention.

\section{Acknowledgements}

None.

\section{Conflict of interest}

None.

\section{References}

1. Geyser M, Smith S. Chest pain prevalence, causes, and disposition in the emergency department of a regional hospital in Pretoria. Afr J Prim Health Care Fam Med 2016 Jun 10;8(1):e1-5. doi: 10.4102/phcfm.v8i1.1048.

2. Opolot JO. Chest pain: an approach for family practice. $S$ Afr Fam Pract 2005 Sep;47(9):30-3.

3. Smulders MW, Kietselaer BLJH, Schalla S, Bucerius J, Jaarsma C, van Dieijen-Visser MP, et al. Acute chest pain in the high-sensitivity cardiac troponin era: a changing role for noninvasive imaging? Am Heart J 2016 Jul;177:102-11.

4. Bruno RR, Donner-Banzhoff N, Söllner W, Frieling T, Müller C, Christ M. The interdisciplinary management of acute chest pain. Dtsch Arztebl Int 2015 Nov 6;112(45):768-79; quiz 780.

5. Haasenritter J, Biroga T, Keunecke C, Becker A, Donner-Banzhoff N, Dornieden K, et al. Causes of chest pain in primary care - a systematic review and meta-analysis. Croat Med J 2015 Oct;56(5):422-30.

6. Huis In 't Veld MA, Cullen L, Mahler SA, Backus BE, Dezman ZDW, Mattu A. The fast and the furious: low-risk chest pain and the rapid rule-out protocol. West J Emerg Med 2017 Apr;18(3):474-8.

7. Baxter SK, Allmark P. Reducing the time-lag between onset of chest pain and seeking professional medical help: a theory-based review. BMC Med Res Methodol 2013 Dec 6;13(1):15. doi: 10.1186/1471-2288-13-15.

8. Wechkunanukul K, Grantham H, Clark RA. Global review of delay time in seeking medical care for chest pain: An integrative literature review. Aust Crit Care 2017 Jan;30(1):13-20.

9. Leslie WS, Urie A, Hooper J, Morrison CE. Delay in calling for help during myocardial infarction: reasons for the delay and subsequent pattern of accessing care. Heart 2000 Aug;84(2):137-41.

10. Van Severen E, Willemsen R, Vandervoort P, Sabbe M, Dinant G-J, Buntinx F. How do patients with chest pain access Emergency Department care? Eur J Emerg Med 2017 Dec;24(6):423-7.

11. Coventry LL, van Schalkwyk JW, Thompson PL, Hawkins SA, Hegney DG. Myocardial infarction, patient decision delay and help-seeking behaviour: a thematic analysis. J Clin Nurs 2017 Jul;26(13-14):1993-2005.

12. Baxter SK, Allmark P. Reducing the time-lag between onset of chest pain and seeking professional medical help: a theory-based review. BMC Med Res Methodol 2013 Dec 6;13(1):15. doi: 10.1186/1471-2288-13-15.

13. Galinski M, Saget D, Ruscev M, Gonzalez G, Ameur L, Lapostolle F, et al. Chest pain in an out-of-hospital emergency setting: no relationship between pain severity and diagnosis of acute myocardial infarction. Pain Pract 2015 Apr;15(4):343-7. 
14. Perkins-Porras L, Whitehead DL, Strike PC, Steptoe A. Pre-hospital delay in patients with acute coronary syndrome: factors associated with patient decision time and home-to-hospital delay. Eur J Cardiovasc Nurs 2009 Mar;8(1):26-33.

15. Meischke H, Ho MT, Eisenberg MS, Schaeffer SM, Larsen MP. Reasons patients with chest pain delay or do not call 911. Ann Emerg Med 1995 Feb;25(2):193-7.

16. Ell K, Haywood LJ, Sobel E, deGuzman M, Blumfield D, Ning JP. Acute chest pain in African Americans: factors in the delay in seeking emergency care. Am J Public Health 1994 Jun;84(6):965-70.
17. Nilsson G, Mooe T, Söderström L, Samuelsson E. Pre-hospital delay in patients with first time myocardial infarction: an observational study in a northern Swedish population. BMC Cardiovasc Disord 2016 May 12;16:93. doi: 10.1186/s12872-016-0271-x.

18. Mumford AD, Warr K V, Owen SJ, Fraser AG. Delays by patients in seeking treatment for acute chest pain: implications for achieving earlier thrombolysis. Postgrad Med J 1999 Feb;75(880):90-5.

19. Newman JD, Davidson KW, Ye S, Shaffer JA, Shimbo D, Muntner P. Gender differences in calls to 9-1-1 during an acute coronary syndrome. Am J Cardiol 2013 Jan;111(1):58-62. 